\title{
Robotics and 3D Printing Training Flourishes within Europe
}

\section{Kenneth OE Sundin*}

Founder and Inspirational Manager, SME Academy, UK

*Corresponding author: Kenneth OE Sundin, Founder and Inspirational Manager, SME Academy, UK, Tel: +70578 5252; E-mail: kenneth.sundin@smeacademy.se Received date: July 14, 2017; Accepted date: August 04, 2017; Published date: August 14, 2017

Copyright: ( 2017 Kenneth OE Sundin. This is an open-access article distributed under the terms of the Creative Commons Attribution License, which permits unrestricted use, distribution, and reproduction in any medium, provided the original author and source are credited.

Citation: Kenneth OE Sundin (2017) Robotics and 3D Printing Training Flourishes within Europe. Adv Robot Autom 6: 169. doi:10.4172/2168-9695.1000169

\section{ROTENA Presents the First Outcomes and Findings}

The project's first activity was to study and determine the conditions under which robotics and 3D printing training flourishes within Europe. The partners therefore undertook different activities: Besides a web research on existing training opportunities in the field, the partners conducted an online survey targeted to SMEs, individuals and training providers. The survey was completed by 150 persons representing all target groups. Some of the first findings can be highlighted as follows:

Very few introductory or basic courses in general

Elements of robotics and 3D printing usually offered as part of electrical or mechanical engineering courses; as a Master's Degree at the second level at some universities, some VETs provide specializations for industrial robotics

Lack of introductory courses to interest and motivate students at earlier levels

Courses are mostly not online, standalone, open, free or massive only a few MOOCs available

Usually focused on advanced or specialized topics (AI, automation), as segments or parts of VET, University education

Difficult to reach individuals outside of the Higher Education system with few options of standalone courses

Offers for 3D printing training even more limited as for robotics.

All findings and results will be summarized in a European Review Report that also includes good practices and recommendation for training providers. The full report as well as a summary will soon be available for free download on the Rotena website.

\section{Training Course Features}

Beginner level: A course for everybody. No previous knowledge required.

Success: Allow someone without knowledge about electronics, robotics and $3 \mathrm{D}$ to successfully complete the course
No need for material: Even without practical material the learners will be able to complete the course

Intuitive: Make it an intuitive and practical course

Free: Use of free software.

\section{Training Modules}

Module 0: Introduction

Module 1: Drawing and Projection

Module 2: 3D Projection and Printing

Module 3: Technology and Assembly of electronic components

Module 4: Algorithm and Microcontrollers

Module 5: Robot Assembly, Programming and Testing.

The course will be ready for testing by the end of the year. Face-toface pilot testing in Portugal and online testing by SMEs, training providers, and individuals.

\section{Training Institutions and Educators}

Having access to the "New Age" Training Module Framework, which can complement your existing technology courses [1].

Adding the Training Modules to your own portfolio of training products/services that you provide to individuals in order to continue to support effective and efficient technology training.

SMEs Having access to a growing pool of individuals with an increasing awareness, and increasing skill set, and who have the skills to take your SME forward to more effectively compete to secure new [2].

\section{References}

1. Rotena (2017) European Robotics/3D Printing Training Survey.

2. Tallinn E (2017) Practical Robotics with 3D printing. Summer School in Europe. 